\title{
An Ultrafast Rechargeable Lithium Metal Battery
}

Xiang Li, ${ }^{\text {a, b, c }}$ Shaohua Guo, ${ }^{\text {a, c* Kezhu Jiang, }}{ }^{\text {a }}$ Yu Qiao, ${ }^{\text {b, c }}$ Masayoshi Ishida ${ }^{\mathrm{b}}$ and Haoshen Zhou ${ }^{\text {a, b, c* }}$

a. Center of Energy Storage Materials \& Technology, College of Engineering and Applied Sciences, National Laboratory of Solid State Microstructures, and Collaborative Innovation Center of Advanced Microstructure, Nanjing University, Nanjing 210093, China.

b. Graduate School of System and Information Engineering, University of Tsukuba, Tennoudai 1-1-1, Tsukuba, 305-8573, Japan

c. Energy Technology Research Institute, National Institute of Advanced Industrial Science and Technology (AIST), Japan. 


\section{Experimental procedure}

$\mathrm{Mn}\left(\mathrm{NO}_{3}\right)_{2}$-containing electrolyte:

$\mathrm{Mn}\left(\mathrm{NO}_{3}\right)_{2} \cdot 6 \mathrm{H}_{2} \mathrm{O}$ was considered as the additive. Calculated and weighted the crystal $\mathrm{Mn}\left(\mathrm{NO}_{3}\right)_{2} \cdot 6 \mathrm{H}_{2} \mathrm{O}$ and put it into a bottle dried in oven overnight. Then dropped the electrolyte (1M LiPF 6 in EC/DEC, (ethylene carbonate/diethyl carbonate, $\mathrm{v}: \mathrm{v}=1: 1)$ ) into the bottle in the glove box. $\mathrm{Mn}\left(\mathrm{NO}_{3}\right)_{2} \cdot 6 \mathrm{H}_{2} \mathrm{O}$ dissolved quickly in the electrolyte and the concentration is $0.1 \mathrm{~mol} / \mathrm{L}$. Considering that the exists of crystal water in $\mathrm{Mn}\left(\mathrm{NO}_{3}\right)_{2} \cdot 6 \mathrm{H}_{2} \mathrm{O}$, molecular sieve was used for dehydration. The electrolyte was prepared for usage after a rest of overnight.

Pre-treatment of lithium metal:

The lithium metal was pressed on one gasket with one press machine and then was covered with $50 \mathrm{uL}$ electrolyte with $\mathrm{Mn}\left(\mathrm{NO}_{3}\right)_{2} \cdot 6 \mathrm{H}_{2} \mathrm{O}$ additive. The electrolyte reacted quickly with lithium metal and the colour of the lithium metal surface turned to black within $1 \mathrm{~min}$. The residual electrolyte covering the lithium metal was washed by DEC several times.

\section{Synthesis of $\mathrm{LiMn}_{2} \mathrm{O}_{4}$ :}

$\mathrm{LiMn}_{2} \mathrm{O}_{4}$ powder was synthesized by solid-state reactions of $\mathrm{LiOH} \cdot \mathrm{H}_{2} \mathrm{O}$ (Wako) and $\mathrm{MnO}_{2}$. The starting materials, $\mathrm{LiOH} \cdot \mathrm{H}_{2} \mathrm{O}$ and $\mathrm{MnO}_{2}$ powder, were mixed at a 1.05:2 $\mathrm{Li}: \mathrm{Mn}$ ratio and put into a corundum pot together with milling balls. The milling pot was sent in a planetary ball-mill machine. The rotation speed of the miller was set to $220 \mathrm{rpm}$ for $10 \mathrm{~h}$. The mixed slurry was dried and calcined at $450{ }^{\circ} \mathrm{C}$ in air for $20 \mathrm{~h}$, then subsequently fired at $700{ }^{\circ} \mathrm{C}$ in air for $48 \mathrm{~h}$ and naturally cooled to room temperature with intermittent regrinding.

\section{Electrochemical tests:}


2032 coin-type cells were used for electrochemical measurements. For all three systems, pretreated-Li metal was the anode, and bare Li metal was also used as the anode in control group. Copper foil was the counter electrode in $\mathrm{Li} \mid \mathrm{Cu}$ system. The same $\mathrm{Li}$ metal was the counter electrode in $\mathrm{Li}$ symmetric system. $\mathrm{LiMn}_{2} \mathrm{O}_{4}$ was the counter electrode in $\mathrm{Li} \mid \mathrm{LiMn} \mathrm{O}_{4}$ system. $\mathrm{LiMn}_{2} \mathrm{O}_{4}$ electrode consisted of active material, acetylene black, and polytetrafluoroethene (PTFE, 12 wt.\%) binder with the weight ratio of 85:10:5. $1 \mathrm{M} \mathrm{LiPF}_{6}$ in EC/DEC was prepared as the electrolyte with a glass fiber film as separator in all systems. The galvanostatic charge-discharge tests were performed by using a Hokuto Denko HJ1001SD8 battery tester at different conditions.

\section{Characterizations:}

The detailed structural information of the SEI was observed using scanning electron microscopy (SEM, TOPCON DS-720 instrument). XPS was characterized by a Thermo Fisher

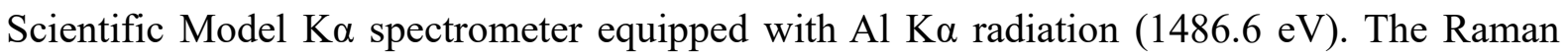
spectra were recorded using a JASCO microscope spectrometer (NRS-1000DT). Before XPS test, the sample was transferred into an Ar glove box and sealed in an airtight container to avoid the exposure with the humidity. For SEM samples, the Li metal was placed onto a SEM sample holder in glove box. The sample holder was sealed in an airtight container and then transferred into the SEM sample loading chamber. Note that the time from opening the sealed container to pumping down the chamber was less than 5 seconds, and we assumed the morphology would not change for such a short time exposed to the open air. 


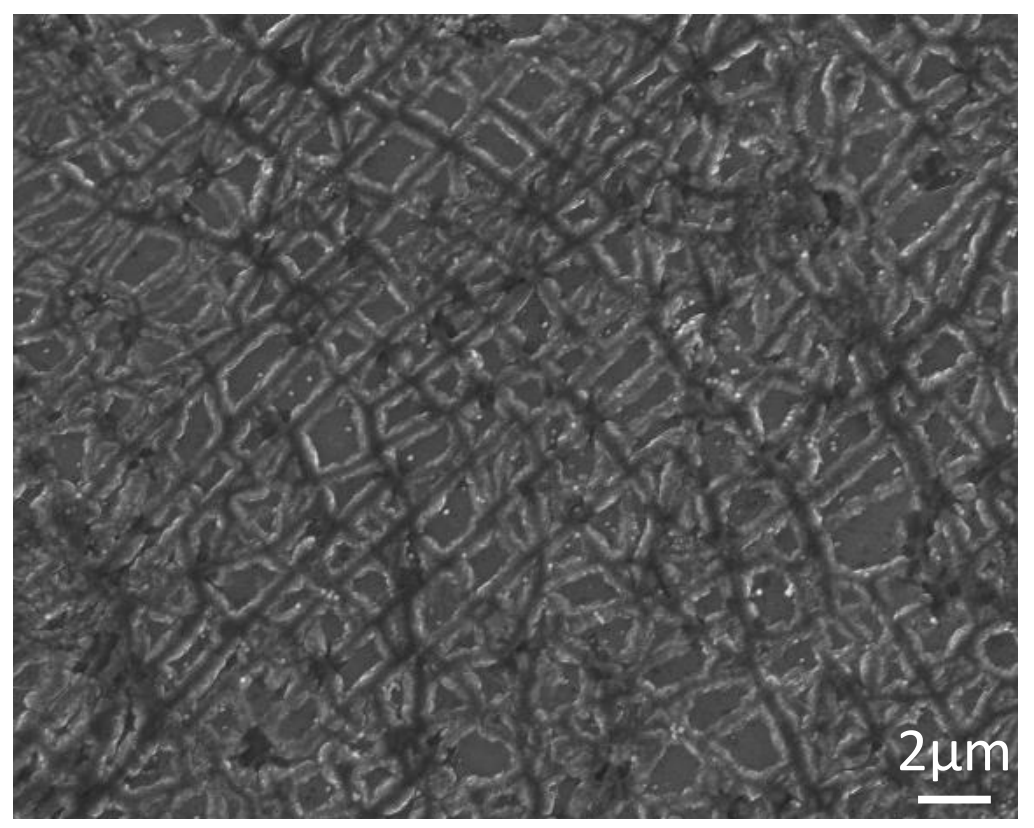

Figure S1. SEM image of the Li metal surface after immersing into electrolyte without additive. 

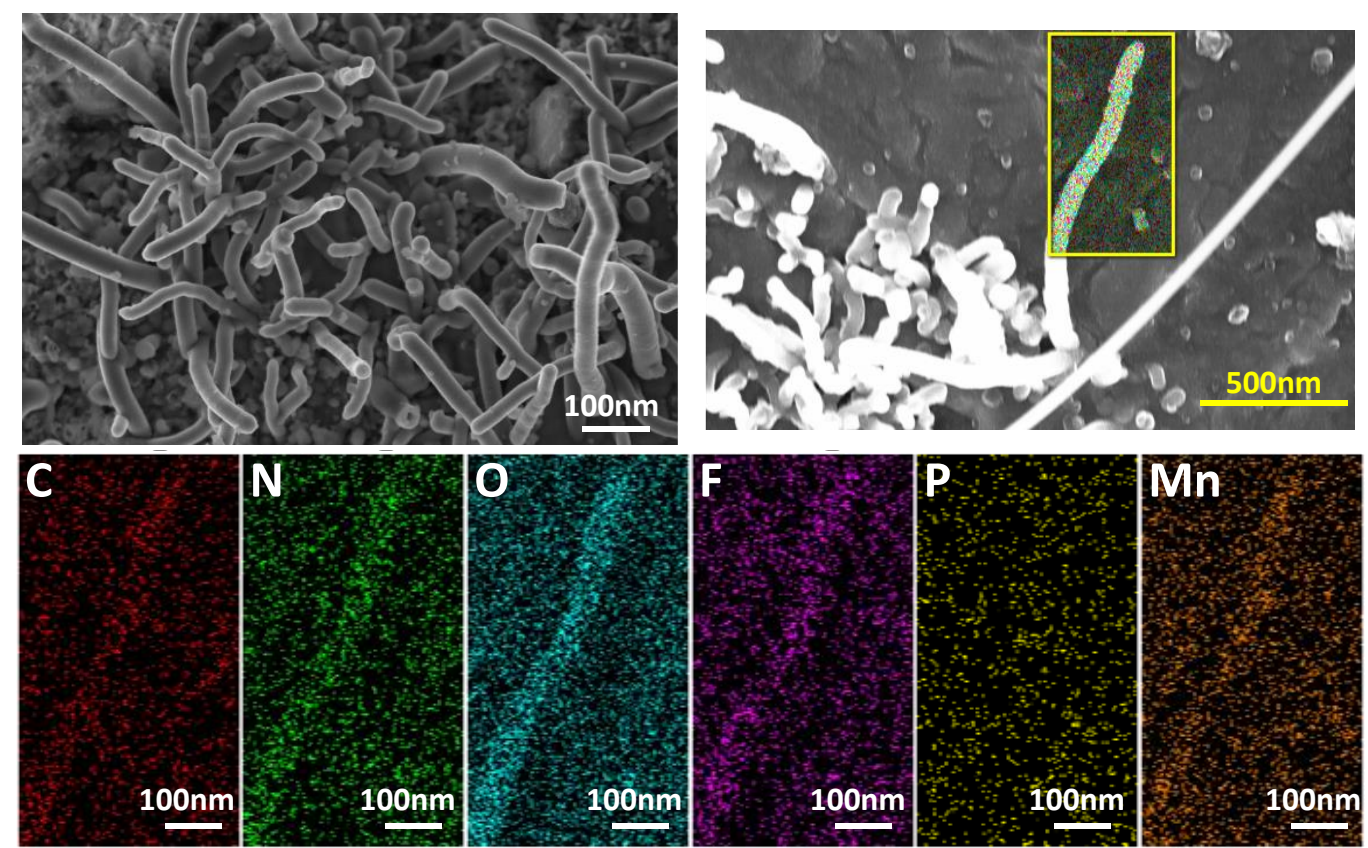

Figure S2. EDX mapping of selected nanotube 

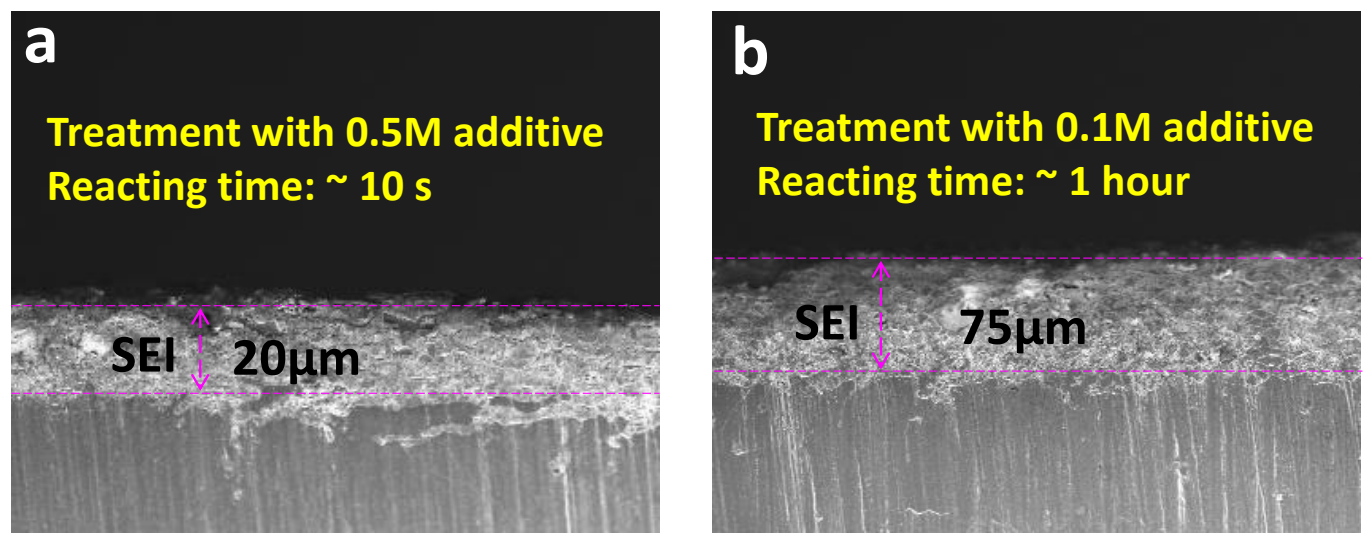

Figure S3. The cross-section of SEI. (a) Treatment with higher content of additive ( $10 \mathrm{~s}$ with $0.5 \mathrm{M}$ additive) and (b) treatment with long time ( 1 hour with $0.1 \mathrm{M}$ additive).

For higher content of additive (Figure S3a), the reaction was faster than that of $0.1 \mathrm{M}$ additive. We controled the reacting time untill the surface of Li metal changed black ( $\sim 10 \mathrm{~s}$ compared with $\sim 1 \mathrm{~min}$ when employing $0.1 \mathrm{M}$ additive). Another sample was reacted with $0.1 \mathrm{M}$ additive electrolyte for about one hour (Figure S3b). Both two samples showed thicker SEI with $20 \mu \mathrm{m}$ and $75 \mu \mathrm{m}$, respectively, comparing with $6 \mu \mathrm{m}$ thickness in Figure 1f. 

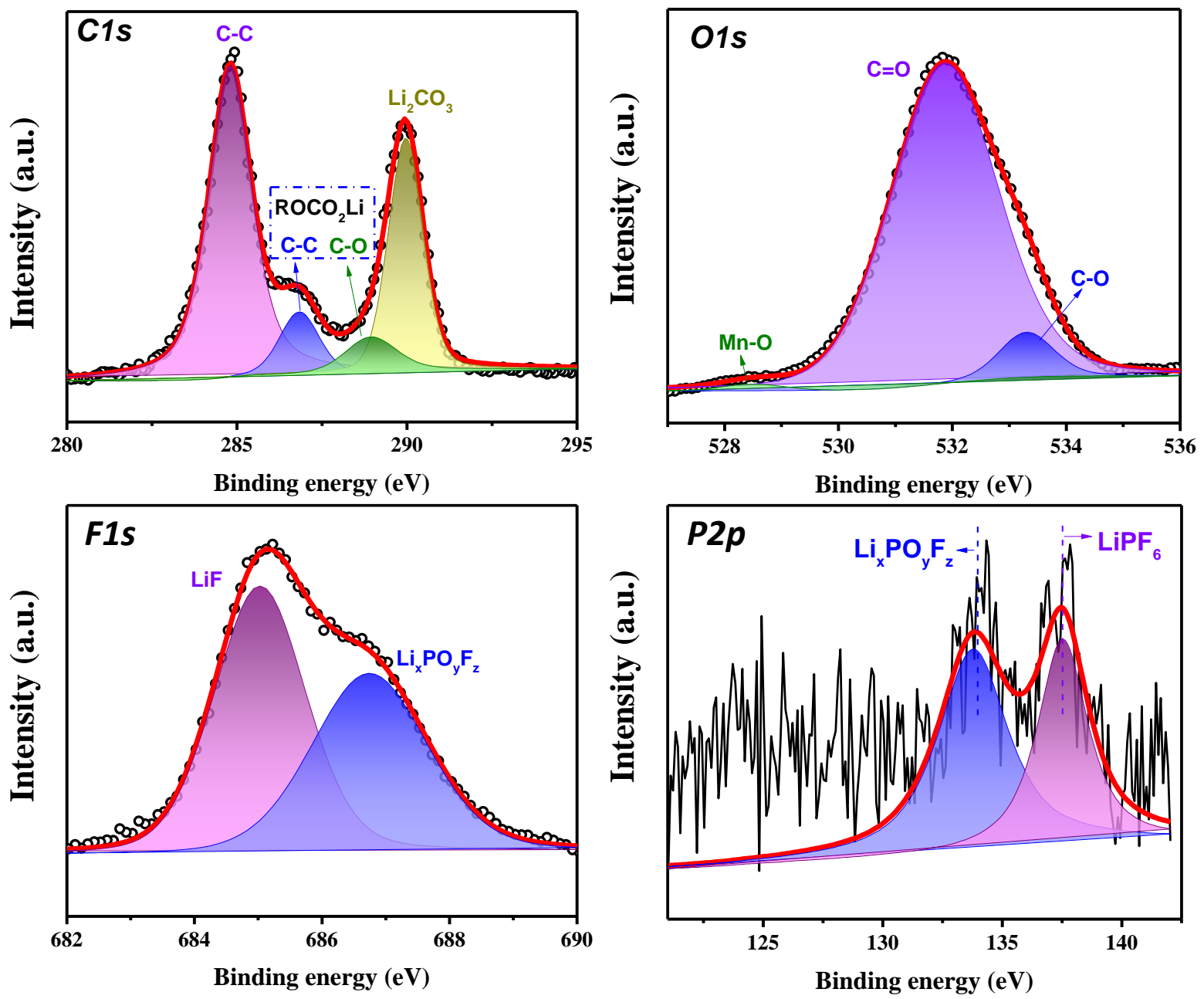

Figure S4. XPS spectra of C1s, O1s, F1s, and P2p collected from SEl immersing in $\mathrm{Mn}\left(\mathrm{NO}_{3}\right)_{2}$ additive electrolyte. 


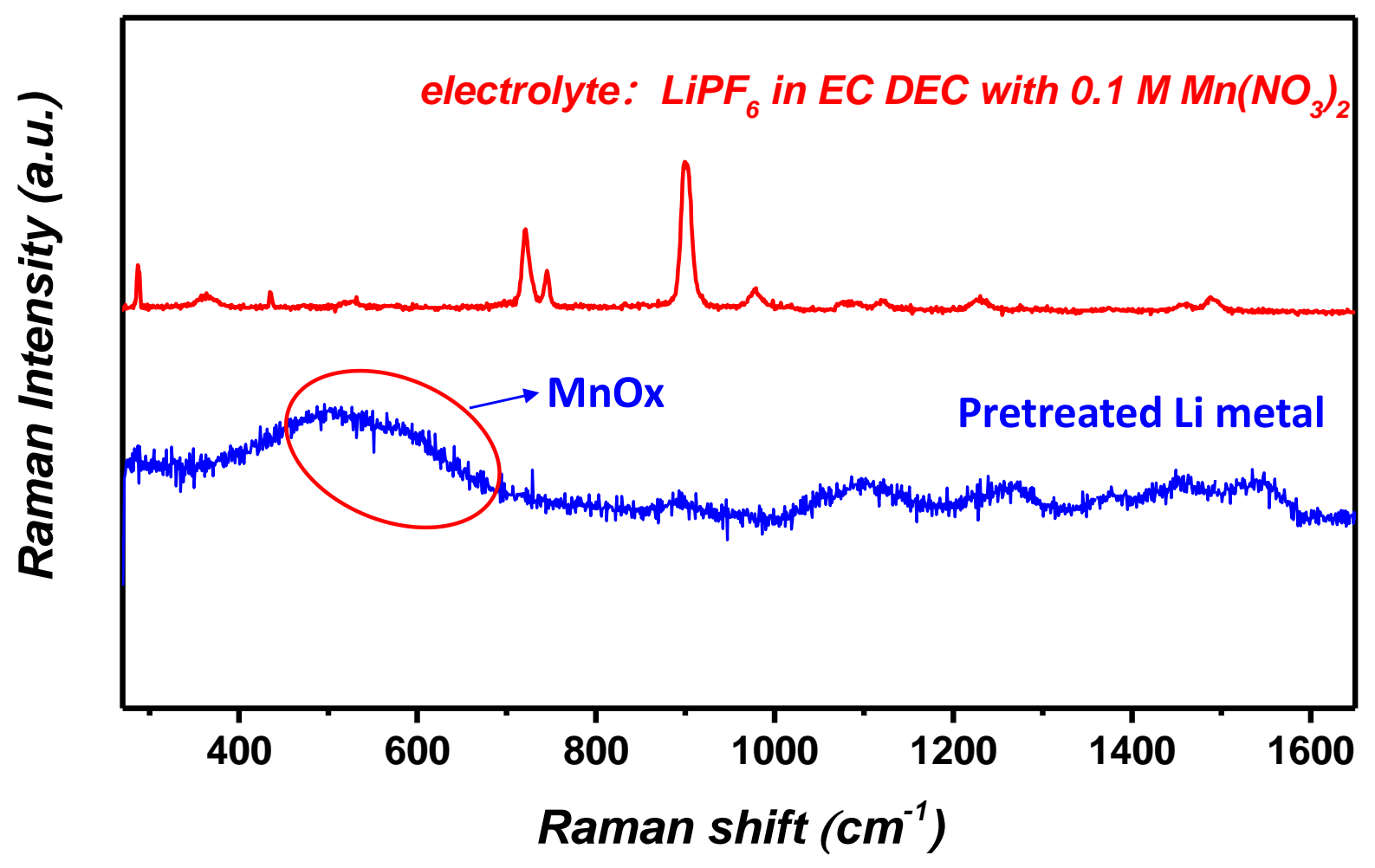

Figure S5. Raman spectra of the pretreated Li metal. The electrolyte with additive is for comparison. 


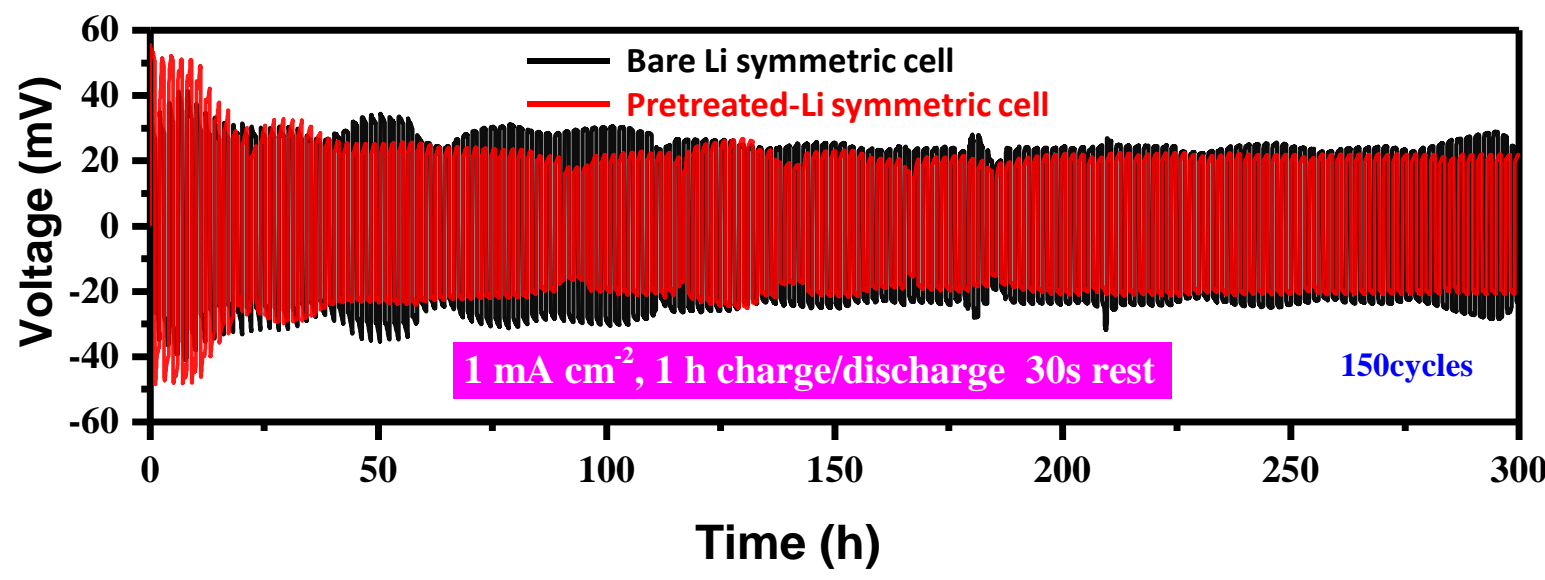

Figure S6. The comparison of galvanostatic striping/plating performance for pretreated-Li symmetric cell (red line) and bare Li symmetric cell at the current of $1 \mathrm{~mA} \mathrm{~cm}{ }^{-2}$ and areal capacity of $1 \mathrm{mAh} \mathrm{cm}^{-2}$. 

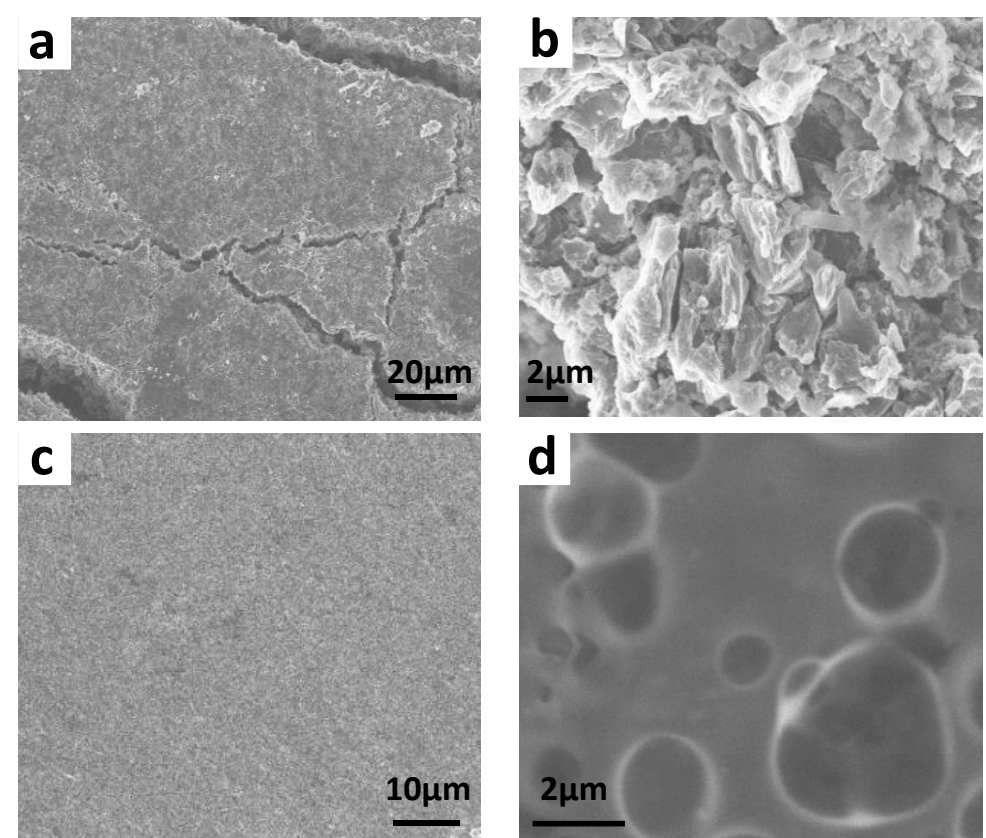

Figure S7. SEM images of Li metal electrodes after cycles at the current density of $20 \mathrm{~mA} / \mathrm{cm}^{-2}$. (a) and (b)

for the pure Li-metal, (c) and (d) for the protected Li-metal.

For the pure Li-metal, the surface was fragile and turned to flawed after cycles (Figure S7a). The surface cannot sustain such a large current density, thus the irregular lithium dendrite formed quickly (Figure S7b). For comparison, the protected Li-metal showed robust surface after cycles (Figure S7c) which benefited from the especial nanotube arrays. The nanotubes reduce the local current density, generating homogenous $\mathrm{Li}^{+}$flux distrubution. Furthermore, the nanotubes could be filled with Li metal, ensuring the stability of the surface (Figure S7d). 

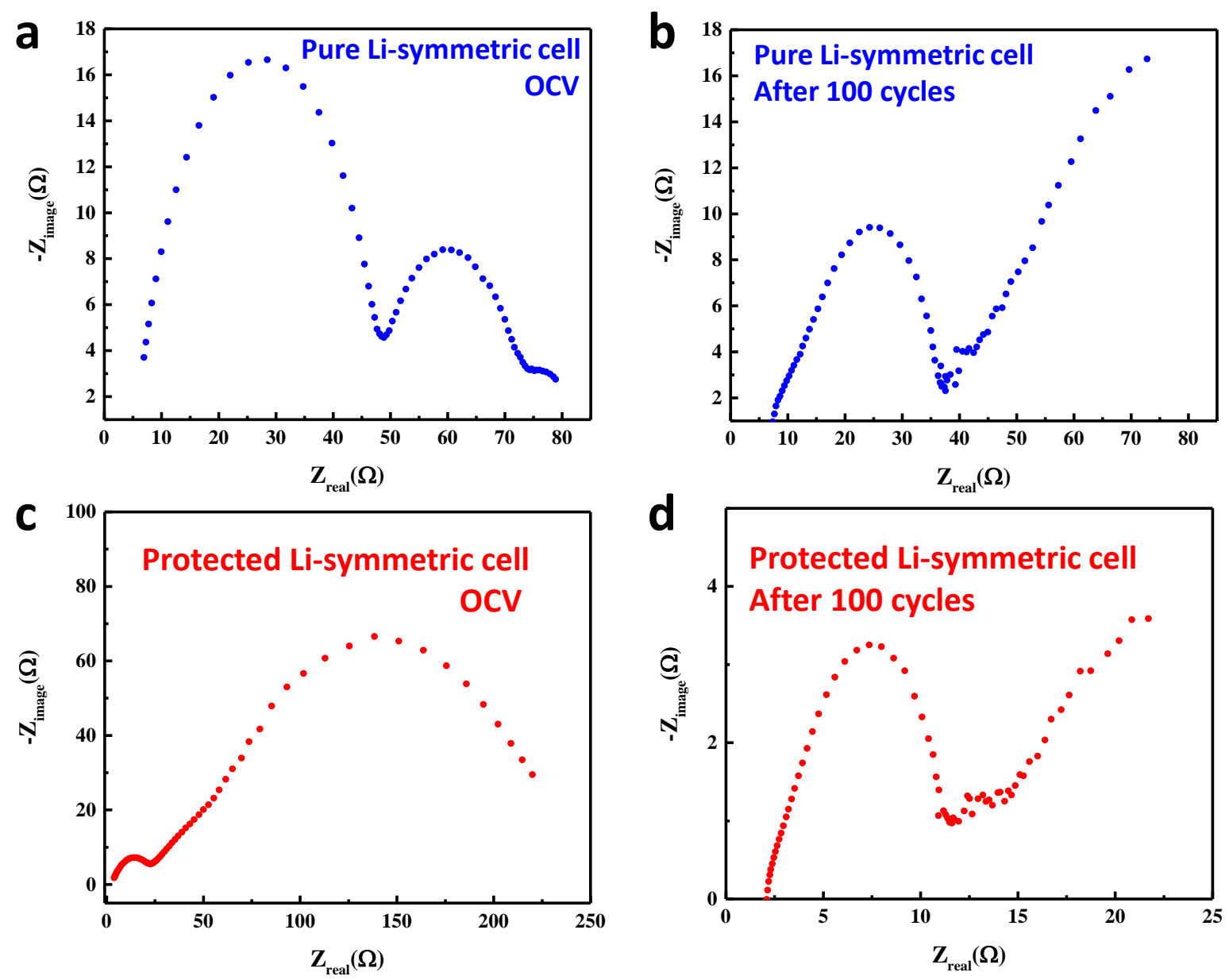

Figure S8. EIS of the Li-symmetric cell. (a) OCV of the pure Li-symmetric cell. (b) Cycled pure Li-symmetric cell. (c) OCV of the protected Li-symmetric cell. (d) Cycled protected Li-symmetric cell.

Electrochemical impedance spectroscopy (EIS) measurements were performed to research the kinetic differences of the pure and protected Li-symmetric cell. The difference is obvious between two cases both in open circuit voltage (OCV) and after cycles. The impedance of pure Li-symmetric cell is $\sim 50 \Omega$ at OCV and decreases to $\sim 40 \Omega$ after cycles. In comparison, the impedance of protected Li-symmetric cell is only half of the pure Li-symmetric cell $(\sim 25 \Omega)$ at OCV and decreases to a tiny value of $\sim 12 \Omega$, demonstrating the enhanced electron- and lithium-ion transport after formation of the stable SEI, which will increase the electrode kinetics and consequently improve the high-rate performance of the protected Li-symmetric cell. 

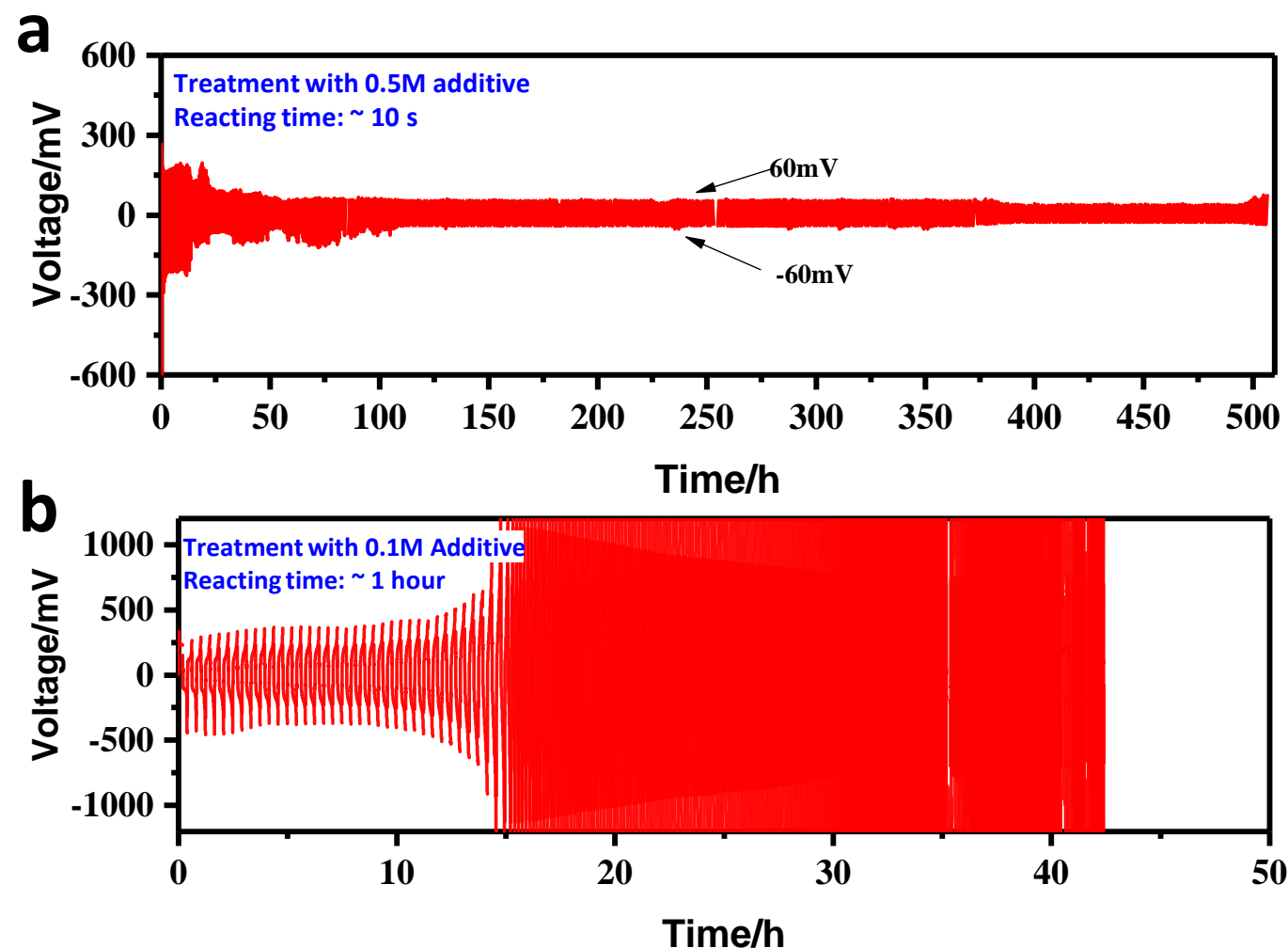

Figure S9. Galvanostatic stripping/plating performance of the pretreated-Li symmetric cell. (a) Treatment of Li metal with higher content of additive ( $\sim 10$ s with $0.5 \mathrm{M}$ additive) and $(\mathrm{b})$ treatment with long time ( 1 hour with $0.1 \mathrm{M}$ additive). The current density is $5 \mathrm{~mA} \mathrm{~cm}{ }^{-2}$.

The thickness of the protective layer has the relationship with the electrochemical performance. It may exist an optimal thickness for the electrochemical performance. For the two cases in Figure S3, we tested the galvanostatic stripping/plating performance at the current density of $5 \mathrm{~mA} \mathrm{~cm}^{-2}$. It was clear that the symmetric cell showed inferior behavior with thicker SEI, especially for the long time treatment sample with $75 \mu \mathrm{m}$ SEI (the cell was failure only less than 20 hours). The cell treated with $0.5 \mathrm{M}$ additive electrolyte showed similar performance with that in Figure 3a. Howerer, the stable voltage $(60 \mathrm{mV})$ is larger than $20 \mathrm{mV}$ showed in Figure $3 \mathrm{a}$, resulting from the thicker SEI. The reaction time between Li metal and the electrolyte is controllable when the content of $\mathrm{Mn}\left(\mathrm{NO}_{3}\right)_{2}$ is $0.1 \mathrm{M}$. When the content is lower than $0.1 \mathrm{M}$, the reaction time will be prolonged, leading to a waste of time. When the content is larger than $0.1 \mathrm{M}$, the reaction is fast and it is not esay to control the SEI. 


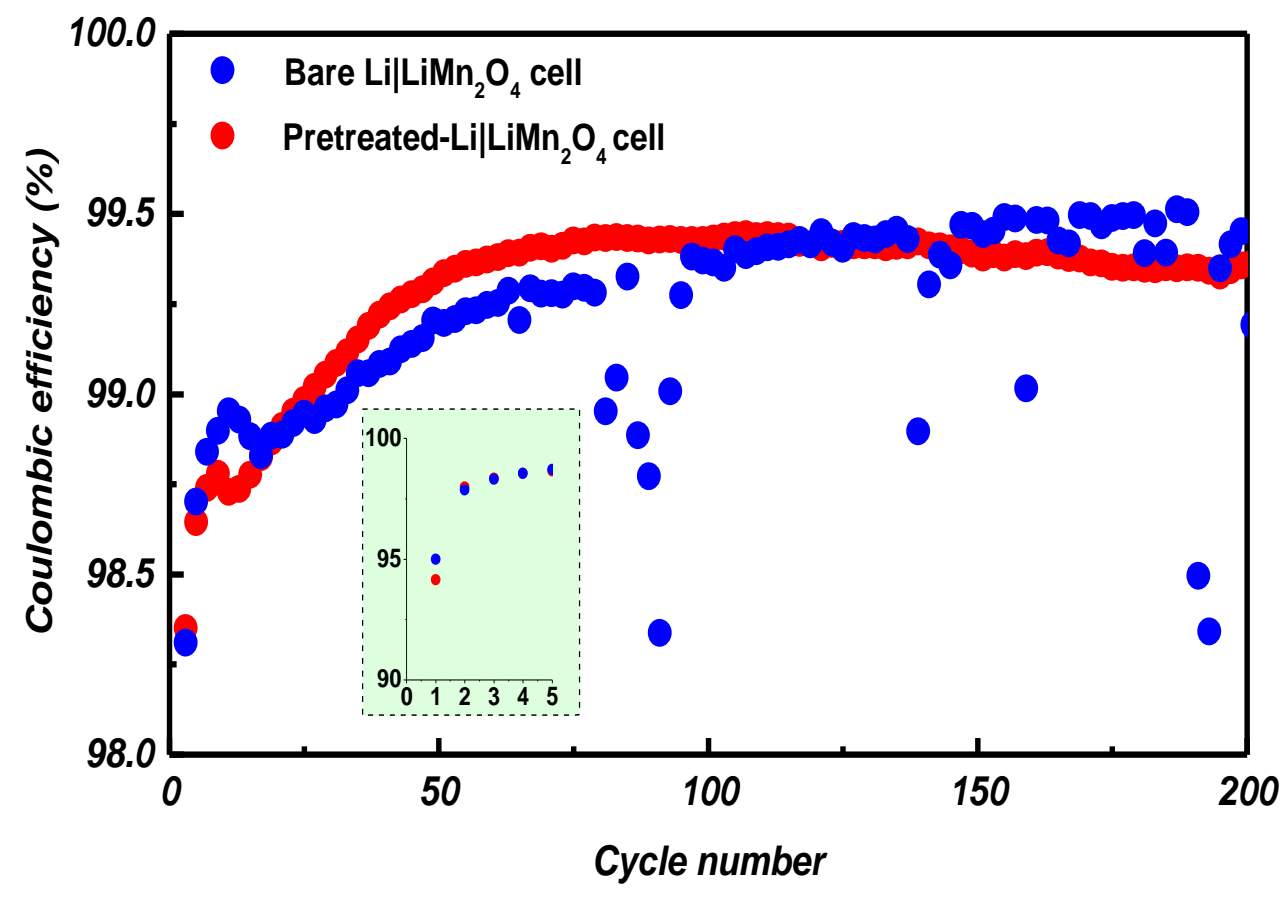

Figure S10. Comparison of coulombic efficiency profiles with bare Li|LiMn${ }_{2} \mathrm{O}_{4}$ cell and Pretreated-

$\mathrm{Li} \mid \mathrm{LiMn}_{2} \mathrm{O}_{4}$ cell for the first 200 cycles. The inset shows the coulombic efficiency of the initial five cycles. 

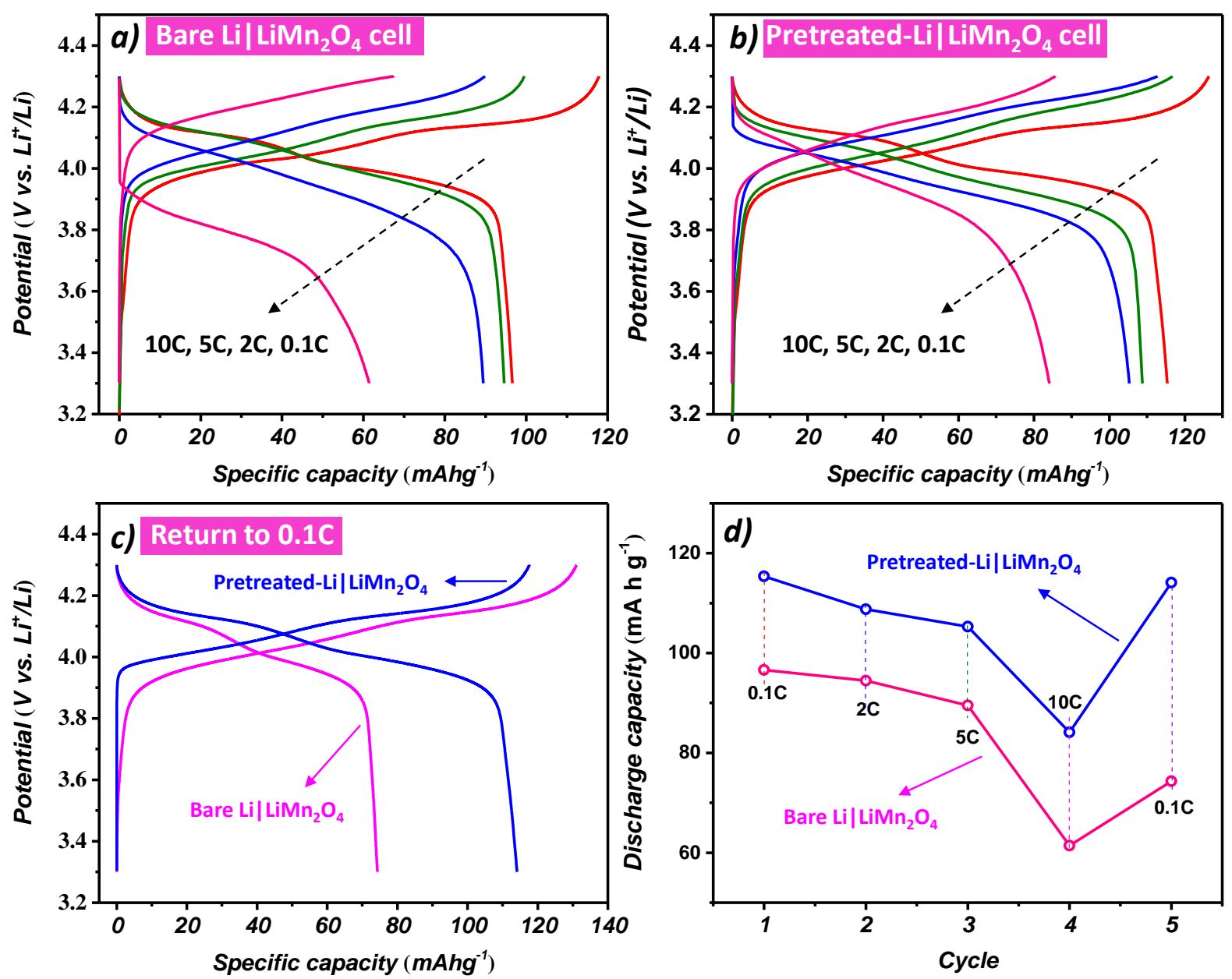

Figure S11. Comparison of rate performance with (a) bare Li| LiMn $\mathrm{LO}_{4}$ cell and (b) pretreated-Li| LiMn $\mathrm{O}_{4}$ cell at the rates of $0.1 \mathrm{C}, 2 \mathrm{C}, 5 \mathrm{C}$ and $10 \mathrm{C}\left(1 \mathrm{C}=148 \mathrm{~mA} \mathrm{~g}^{-1}\right)$. (c) The charge/discharge profiles of two cells when the current density returned to $0.1 \mathrm{C}$ after the rates test. (d) The discharge capacity of two cells at different rates. The temperature is $55^{\circ} \mathrm{C}$ and the potential window is $3.3 \sim 4.3 \mathrm{~V}$. 

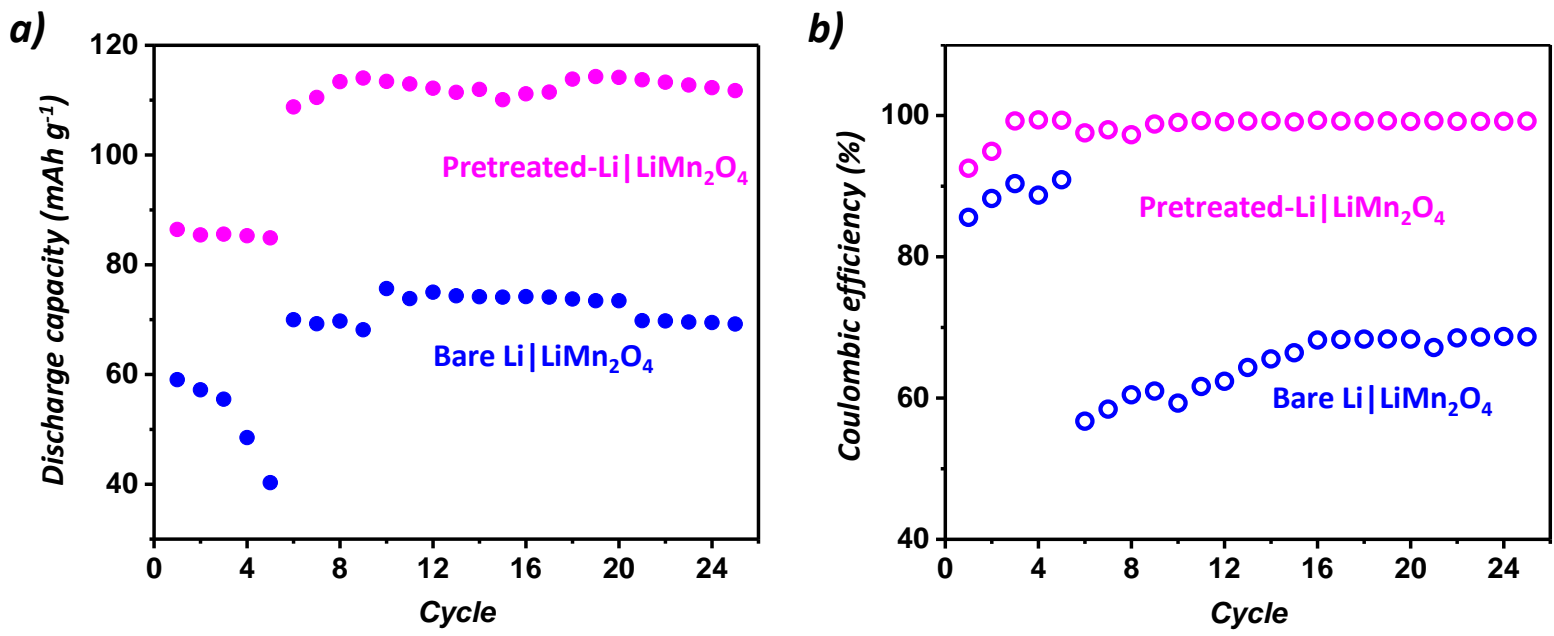

Figure S12. Recovery capability profiles of (a) discharge capacity and (b) coulombic efficiency with the initial

5 cycles in $10 \mathrm{C}$ and subsequent cycles in $0.1 \mathrm{C}$ at $55^{\circ} \mathrm{C}$. The potential window was set to $3.3 \sim 4.3 \mathrm{~V}$. 
Table S1. Comparison of recent literatures on high current density performances of Li anodes

\begin{tabular}{|c|c|c|c|}
\hline Symmetric cell & Current density $\left(\mathrm{mA} \mathrm{cm}^{-2}\right)$ & Overpotential (mV) & Reference \\
\hline $\mathrm{TiC} / \mathrm{C} / \mathrm{Li}$ & 10 & $\sim 500$ & [1] \\
\hline $\begin{array}{l}\text { Li-ion conductive nanocomposite } \\
\text { electrode }\end{array}$ & 10 & $\sim 300$ & [2] \\
\hline $\begin{array}{c}\text { Li|Li cell with a 4M LiFSI-DME } \\
\text { electrolyte }\end{array}$ & 10 & $\sim 220$ & [3] \\
\hline 3D Cellular Graphene Li & 10 & $\sim 200$ & [4] \\
\hline ZnO/Carbon Li & 10 & $\sim 80$ & [5] \\
\hline $\begin{array}{l}\text { Li|Li cell with LiF LiTFSI/DOL-DME } \\
\text { solution }\end{array}$ & 10 & $\sim 20$ & [6] \\
\hline Polished Li & 10 & $\sim 25$ & [7] \\
\hline Li| LiFSI/[C $\left.\mathrm{C}_{3} \mathrm{mPyr} \mathrm{P}^{+}\right]\left[\mathrm{FSI}^{-}\right] \mid$Li cell & 10 & $\sim 11$ & [8] \\
\hline $\begin{array}{l}\text { Li|Li cell with } 1 \mathrm{M} \text { LiTFSI DOL/DME- } \\
\qquad 0.1 \mathrm{M} \mathrm{LiNO} \\
\end{array}$ & 15 & $\sim 500$ & [9] \\
\hline Pretreated-Li with $\mathrm{LiPF}_{6}$ in $\mathrm{EC} / \mathrm{DEC}$ & 20 & $\sim 60$ & This work \\
\hline
\end{tabular}


References:

[1] S. Liu, X. Xia, Y. Zhong, S. Deng, Z. Yao, L. Zhang, X. B. Cheng, X. Wang, Q. Zhang, J. Tu, Adv. Energy. Mater., 2018, 8, 1702322.

[2] D. Lin, J. Zhao, J. Sun, H. Yao, Y. Liu, K. Yan, Y. Cui, Proc. Natl. Acad. Sci., USA 2017, $114,4613$.

[3] J. Qian, W. A. Henderson, W. Xu, P. Bhattacharya, M. Engelhard, O. Borodin, J. G. Zhang, Nat. Commun., 2015, 6, 6362.

[4] W. Deng, X. Zhou, Q. Fang, Z. Liu, Adv. Energy., Mater. 2018, 1703152.

[5] L. Wang, X. Zhu, Y. Guan, J. Zhang, F. Ai, W. Zhang, Y. Xiang, S. Vijayan, G. Li, Y. Huang, Energy Storage Mater., 2018, 11, 191.

[6] R. Miao, J. Yang, X. Feng, H. Jia, J. Wang, Y. Nuli, J. Power Sources, 2014, 271, 291.

[7] Y. Gu, W.-W. Wang, Y.-J. Li, Q.-H. Wu, S. Tang, J.-W. Yan, M.-S. Zheng, D.-Y. Wu, C.H. Fan, W.-Q. Hu, Z.-B. Chen, Y. Fang, Q.-H. Zhang, Q.-F. Dong, B.-W. Mao, Nat. Commun., $2018,9,1339$.

[8] A. Basile, A. I. Bhatt, A. P. O'Mullane, Nat. Commun., 2016, 7, 11794.

[9] L. Li, S. Basu, Y. Wang, Z. Chen, P. Hundekar, B. Wang, J. Shi, Y. Shi, S. Narayanan, N. Koratkar, Science, 2018, 359, 1513. 